\title{
SUCCESSFUL TREATMENT OF SEVERE THYROTOXICOSIS WITH RADIOIODINE THERAPY IN A PATIENT WITH THYROTOXIC CARDIOMYOPATHY
}

\section{Arambewela MH, Kaluarachchi V, Bulugahapitiya U}

Colombo South Teaching Hospital.

\section{ABSTRACT}

Thyrotoxic cardiomyopathy (TCM) is a potential life threatening complication of thyrotoxicosis which is potentially reversible with early achievement of euthyroid state. Management of severe thyrotoxicosis in the presence of TCM is a challenging task, especially when thioamides are contraindicated.

A $58 \mathrm{yr}$ old male with poorly controlled Grave's disease of 10 years presented with worsening symptoms of thyrotoxicosis and leg swelling. On examination he was thyrotoxic with a smooth diffuse goiter and also had inactive Grave's orbitopathy. He had irregularly irregular pulse rate, grossly elevated jugular venous pulses, enlarged heart with tricuspid regurgitation and pulmonary hypertension. FT4 was $>8.34 \mathrm{ng} / \mathrm{dl}(0.8-1.6 \mathrm{ng} / \mathrm{dl})$, free T3 was 20.39 $\mathrm{pg} / \mathrm{ml}(2.3-4.3 \mathrm{pg} / \mathrm{ml})$ and TSH was $0.01 \mathrm{mU}(0.5-5.0 \mathrm{mU} / \mathrm{L})$. Serial ECGs showed slow atrial fibrillation with transient complete hear block and echocardiogram showed dilated TCM. He had pancytopenia, most likely resulting from concurrent carbimazole therapy. Medical management of cardiomyopathy was initiated along with lithium, prednisolone and judicious use of beta blockers to control his thyroid status. Within one week he was subjected to radioactive iodine (RAI) therapy following which he was rendered euthyroid .

RAI is a safe mode of definitive therapy in patients with TCM provided carful stabilization of underlying cardiac status. Early definitive therapy is required to achieve euthyroid status to minimize irreversible TCM.

Keywords: Thyrotoxicosis, cardiomyopathy, radioactive iodine therapy.

\section{INTRODUCTION}

Thyrotoxic cardiomyopathy (TCM) is a potential life threatening complication of thyrotoxicosis. It is a cause for reversible cardiomyopathies and in approximately one third of patients with TCM may be reversed with the permanent resolution of hyperthyroidism(1). Prolonged duration of poorly controlled thyroid status, male gender and advanced age are predictors of irreversible TCM. Managing severe thyrotoxicosis in the presence of TCM can be challenging especially when thioamides are contraindicated. We report a case on the successful control of severe thyrotoxicosis with radioactive iodine therapy (RAI) in a patient with TCM and carbimazole induced pancytopaenia.

\section{CASE}

A 58-year-old Sri Lankan male, diagnosed with Grave's disease (GD) for 10 years duration, presented with episodic palpitations, presyncope, sweating, loose stools and ankle swelling. He has had poor disease control and had defaulted clinic follow up and was self-medicating with carbimazole $45 \mathrm{mg}$ daily. There was no history of fever or central nervous system instability.

On examination he was emanciated, sweating and tremulous with smooth diffuse goiter and bilateral pitting ankle edema. He was anicteric, afebrile and oriented. He had orbitopathy with clinically inactive eye disease. Pulse rate was 70 beats per minute and irregularly irregular. Blood pressure was 130/70. Jugular venous pulse was elevated to the level of his ear lobes. He had a shifted cardiac apex, tricuspid regurgitant murmur, loud P2 and a pulsatile liver.

Serial electrocardiograms showed slow atrial fibrillation (AF) with transient complete heart block, and chest X-ray demonstrated a grossly dilated heart with relatively clear lung fields. Echocardiogram showed severely dilated right atrium and ventricle with severe tricuspid regurgitation and moderate pulmonary hypertension. Left ventricle was slightly dilated with an ejection fraction of $60 \%$. His Free T4 (FT4) levels were $>8.34 \mathrm{ng} / \mathrm{dl}(0.8-1.6 \mathrm{ng} / \mathrm{dl})$, free T3 levels were $17.39 \mathrm{pg} / \mathrm{ml}(2.3-4.3 \mathrm{pg} / \mathrm{ml})$ and TSH was $0.01 \mathrm{mU}(0.5-5.0 \mathrm{mU} / \mathrm{L})$. His full blood count (FBC) 
revealed pancytopaenia with haemoglobin of $10 \mathrm{~g} / \mathrm{dl}$, white blood cell count of $3,140 \times 10^{9} / \mathrm{L}$ with absolute neutrophil count of $942 \times 10^{9} / \mathrm{L}$ and platelets of 60,000 . ESR was $30 \mathrm{~mm}$ in $1^{\text {st }}$ hour and C Reactive Protein was $4 \mathrm{mg} / \mathrm{l}(<6 \mathrm{mg} / \mathrm{L})$. He had mildly high aspartate aminotransferase (AST) $55 \mathrm{U} / \mathrm{L}$ with normal levels of alanin transferase (ALT), albumin and globulin levels. Renal functions were normal. He was diagnosed with severe thyrotoxicosis complicated with thyrotoxic cardiomyopathy and carbimazole induced pancytopaenia.

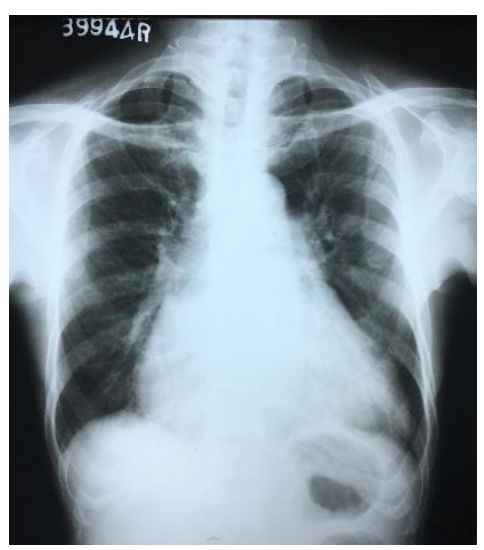

\section{Figure 1 - CXR showing a dilated heart}

His cardiomyopathy was managed with diuretics, warfarin, sildenafil and judicious use of beta blocker. Due to pancytopaenia, carbimazole was omitted and he was started on lithium $500 \mathrm{mg}$ thrice daily and prednisolone $30 \mathrm{mg}$ daily. Following omission of carbimazole his haematological indices improved within 4 days. As he was at high risk of developing lithium toxicity, he was well hydrated and monitored for lithium toxicity both clinically and biochemically. Within a week he was subjected to radioactive iodine therapy (RAI) at a dose of $20 \mathrm{mCi}$ as definitive control of thyrotoxicosis was required urgently. Beta blockers were judiciously used up to two weeks following RAI therapy to block the effect of thyroxin on the heart in the rare event of thyroid crisis. He developed symptomatic resolution within one week and his FT4 dropped to $0.98 \mathrm{ng} / \mathrm{dl}$ following one month of treatment with RAI.

\section{DISCUSSION}

Thyrotoxicosis is common disorder with a prevalence of $3 \%$ in females and $0.3 \%$ in males in iodine replete areas. Thyrotoxic cardiomyopathy (TCM) is a life threatening condition associated with morbidity and mortality. The prevalence of dilated TCM in thyrotoxicosis is $1 \%$ and one third of these cases are irreversible (1).

TCM is defined by myocardial damage caused by the toxic effects of excessive thyroid hormones resulting in alterations in energy production by myocytes, intracellular metabolism and myofibril contractile function ${ }^{1}$. Main manifestations of TCMP are left ventricular hypertrophy, heart rhythm disturbances (commonly AF), dilation of heart chambers with heart failure (HF), pulmonary hypertension, and diastolic dysfunction.

Atrial fibrillation which is the commonest arrhythmia in thyrotoxicosis is attributed to the high $\beta$ adrenoreceptor density at the surface of atrial cardiomyocytes making it sensitive to the arrhythmogenic effects of thyroid hormone(1). Second or third degree heart blocks complicating thyrotoxicosis is rare and likely due to the interstitial inflammation of the AV node, His-bundle and it's branches(2). Pulmonary hypertension develops due to spasm of pulmonary arterioles causing increase in pulmonary resistance. Heart failure (HF) in thyrotoxicosis occurs due to the isotonic contraction (volume overload) of left ventricle and mixed overload (both volume and resistance overload) of right ventricle. Thus right ventricular HF is more common in hyperthyroid state. Concomitant tricuspid valve insufficiency and regurgitation can worsen the situation. A possible mechanism for valve involvement in GD is the synthesis of glycosaminoglycan in endocardium (which is similar to its presence in the pathogenesis of ophthalmopathy) leading to the thickening of valve cusps(1). 


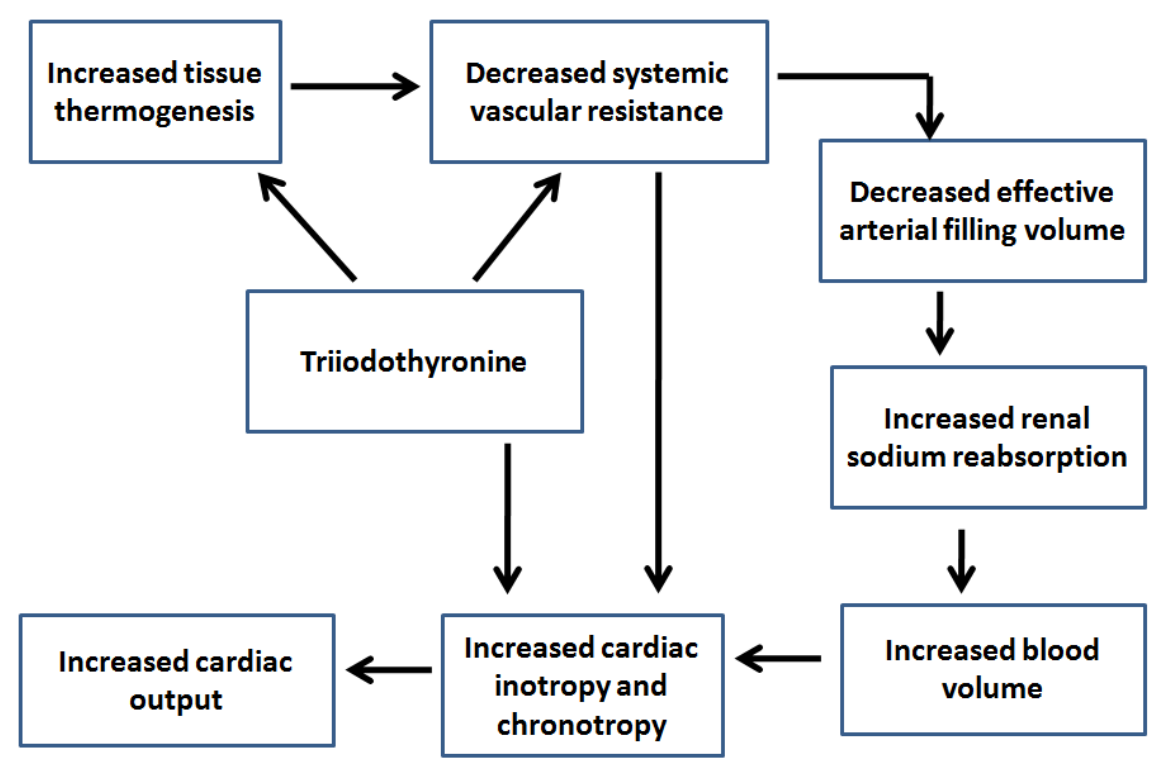

Figure 2 - Effects of Thyroid Hormone on Cardiovascular Hemodynamics(1)

Duration of hyperthyroidism, male sex and advanced age are the main predictors of development of TCM (1). Most studies agree that once the effect of thyroid hormones is eliminated, myocardial damage may be reversible in patients with less than 6 months disease duration(3-5). Persistent euthyroid state is of great importance in improving cardiovascular prognosis. Long term medical management most often results in poor disease control or unacceptable side effects, as was the case in our patient who developed carbimazole induced pancytopaenia. The choice of definitive therapy (radioactive iodine/ surgery) is not always easy in these patients. Due to unfavourable cardiac status these patients are poor surgical candidates and therefore RAI becomes the more favorable option. In the past, there had been some safety concerns on RAI induced thyroiditis and thyroid storm following therapy with RAI. However these complications are extremely rare and controversial(6.7). Studies done on the safety of RAI have demonstrated that it was well tolerated even in patients with severe thyrotoxicosis with very high levels of thyroid hormones(8). In another study of patients with thyrocardiac disease treated with RAI, no worsening of thyrotoxicosis was observed(9).

However, RAI can induce a short term increase of thyroid hormone levels(10). The American thyroid association 2016 guidelines recommends the use of carbimazole, before and after RAI treatment in patients with severe hyperthyroidism, the elderly, and those with comorbidities (cardiac, pulmonary, renal dysfunction, infection and poorly controlled daiebtes etc) that puts them at risk of developing complications due to worsening of thyrotoxicosis. The patient should be medically stable and beta blockers should be used judiciously in preparation for RAI therapy.

Our patient with dilated TCM and carbimazole induced pancytopenia successfully underwent RAI therapy within one week of presentation to our unit, and was rendered euthyroid within a month. However due to long standing thyrotoxicosis which had not been under control, reversibility of dilated cardiomyopathy cannot be expected.

\section{CONCLUSION}

RAI therapy is a safe definitive mode of therapy for patients with severe thyrotoxicosis and TCM. However careful stabilization of the underlying cardiac condition with the judicious use of beta blockers is required in preventing the complications which can arise in the extreme rare event of thyroid storm in such patients. Early and permanent achievement of euthyroid status is vital in reversing TCM. 


\section{REFERENCES}

1. Babenko A Y, Bairamav A A, Grineva $\mathrm{E} N$ et al. Thyrotoxic cardiomyopathy. DOI: 10.5772/29331

2. Osman F, Ayuk J,Dale J etal. Thyroxin with heart block. JRSOc Med 2000;94(7):346-348.

3. Sgarbi J A, Villaça F G, Garbeline B, H. E. Villar H E , Romaldini J H, "The effects of early antithyroid therapy for endogenous subclinical hyperthyroidism in clinical and heart abnormalities." Journal of Clinical Endocrinology and Metabolism 2003;88(4): 1672-1677.

4. Dörr M, Wolff B, Robinson D M et al. "The association of thyroid function with cardiac mass and left ventricular hypertrophy." Journal of Clinical Endocrinology and Metabolism 2005;90(2):673-677.

5. Nagarakanti R, Whellan D, Rubin S, and Mather $P$ J. "Reversible cardiomyopathies." Cardiology in Review 2007;15(4):178-183, 2007.

6. Koornstra J J, Kerstens M N, Hoving J, Visscher K J, Schade J H, Gort H B, et al. Clinical and biochemical changes following 131I therapy for hyperthyroidism in patients not pretreated with antithyroid dung. Neth J Med 1999; 55: 215-221.

7. Sheeler L R, Skillern P G, Schumacher O P, Eversman JJ. Radioiodine-induced thyroid storm: a point of controversy. Am J Med 1998; 76: A98.

8. Vijayakumara V, Nusynowitz M L, Ali S. Is it safe to treat hyperthyroid patients with I-131 without fear of thyroid storm? Annals of Nuclear Medicine 2006;6:383-385

9. Delit C, Silver S, Yohalem SB, Segal RL . Thyrocardiac disease and its management with radioactive iodine I-131. JAMA;176:262-267.

10. Burch H B, Solomon B L, Cooper D S, Ferguson P, Walpert N, Howard R. The effect of antithyroid drug pretreatment on acute changes in thyroid hormone levels after (131)I ablation for Graves' disease. J Clin Endocrinol Metab 2001; 86:30163021 